\title{
Biomechanism of impact resistance in the woodpecker's head and its application
}

\author{
WANG LiZhen ${ }^{1 \dagger}$, LU Shan ${ }^{1,2 \dagger}$, LIU XiaoYu ${ }^{1}$, NIU XuFeng ${ }^{1}$, WANG Chao ${ }^{1}$, NI YiKun ${ }^{1}$, \\ ZHAO MeiYa ${ }^{1}$, FENG ChengLong $^{1}$, ZHANG Ming ${ }^{3}$ \& FAN YuBo ${ }^{1 *}$ \\ ${ }^{1}$ Key Laboratory for Biomechanics and Mechanobiology of Ministry of Education, School of Biological Science and \\ Medical Engineering, Beihang University, Beijing 100191, China; \\ ${ }^{2}$ Science China Press, Beijing 100717, China; \\ ${ }^{3}$ Interdisciplinary Division of Biomedical Engineering, the Hong Kong Polytechnic University, Hong Kong, China
}

Received January 25, 2013; accepted March 24, 2013; published online July 4, 2013

\begin{abstract}
The woodpecker does not suffer head/eye impact injuries while drumming on a tree trunk with high acceleration (more than $1000 \times g$ ) and high frequency. The mechanism that protects the woodpecker's head has aroused the interest of ornithologists, biologists and scientists in the areas of mechanical engineering, material science and electronics engineering. This article reviews the literature on the biomechanisms and materials responsible for protecting the woodpecker from head impact injury and their applications in engineering and human protection.
\end{abstract}

review, biomechanics, woodpecker, head injury, application

Citation: Wang L Z, Lu S, Liu X Y, et al. Biomechanism of impact resistance in the woodpecker's head and its application. Sci China Life Sci, 2013, 56: 715-719, doi: 10.1007/s11427-013-4523-Z

Traumatic brain injury as a consequence of head impact injury has been a leading cause of morbidity and death in war, aviation and road accidents and sports collisions [1-3]. However, the woodpecker repeatedly strikes its head against trees without suffering head injury when drumming a trunk continually at a speed of 6-7 $\mathrm{m} \mathrm{s}^{-1}$ and acceleration of $\sim 1000 \times g$ [4-7]. The woodpecker rhythmically drums surfaces such as dead tree limbs and metal poles with its beak to catch worms to eat, attract a mate or announce its territorial boundaries $[7,8]$. The woodpecker's resistance to head impact injury is a prime example of adaptive natural evolution over millions of years [9], and has been of interest not only to ornithologists and biologists but also to researchers in the fields of mechanical engineering, medical engineering, material science and electronics engineering [4-7,10-13].

$\lceil$ Contributed equally to this work

* Corresponding author (email: yubofan@buaa.edu.cn)
Researchers have explored the mechanism of how a woodpecker avoids head impact injury [4-6,14,15] and searched for clues that will help in developing a bionics shock-absorbing system or device for engineering purposes or human protection [10-13]. This paper presents an overview of the biomechanism that prevents the woodpecker from suffering head impact injury and its applications.

\section{Biomechanism of impact resistance in a woodpecker's head}

The woodpecker is believed to have adapted to impact forces such that it can drum rapidly without suffering head impact injury [4-8,16-22]. Classic ornithological, psychiatric and biomechanical studies suggested the following principal factors.

First, it was suggested that the woodpecker made a per- 
fectly perpendicular strike to eliminate the torsional shear force that would tear the meninges or cause concussion $[8,14,15,20]$. The ornithologist Sielmann found that the spotted woodpecker makes 35-44 strikes in 2.1-2.69 s, and the drumming is thus too fast to record using video at 24 frames per second [23]. May et al. [5] analyzed the drumming of a living pileated woodpecker (Dryocopus pileatus) using a high-speed camera (400 frames per second in color and 2000 frames per second in black and white) and found that the trajectories of the vertex and the center of the head were basically linear. The woodpecker's brain was virtually free of rotational forces that might result in injury when the woodpecker struck a trunk at a maximum pre-impact velocity of $749 \mathrm{~cm} \mathrm{~s}^{-1}$ and deceleration of $1200 \times \mathrm{g}$. However, a curved trajectory was observed using two synchronous high-speed cameras recording at 2000 frames per second when the great spotted woodpecker (Dendrocopos major) struck a sensor and metal cage (Photron Fastcam SA-3, San Jose, California, USA) in our previous study [6]. A related bird, the Eurasian hoopoe (Upupa epops), was also recorded pecking different objects such as foam, a metal cage, and a sensor, and it was found that both were linear and angular accelerations during pecking. The peak linear velocity and deceleration were significantly higher for the woodpecker than for the hoopoe whereas the peak angular velocity and deceleration were closer for the two birds [6]. Doubt was thus cast on the centripetal theory of a straight trajectory preventing brain injury. In addition, the Holbourn equation contains many assumptions. He thought that the rotational acceleration required to produce injury in brains with similar properties and shapes is inversely proportional to the two-thirds power of their mass [20]. It was developed for forces of relatively long duration $(>6.5 \mathrm{~ms})$ and does not apply to short impulse loading. It assumes that the crucial variable is the brain mass and that all brains have similar properties, shapes and cerebrospinal fluid flotation effects. There is considerable controversy related to the biomechanics of the effect of linear acceleration and angular acceleration on head impact injury [24]. Therefore, the linear trajectory of the woodpecker head should not be used as a basis for the biomechanism of the woodpecker's resistance to head impact injury.

The unique anatomical structure of the woodpecker's head has been another important consideration. The woodpecker has special macromorphology such as strong neck muscles, a long hyoid bone, and a stout, sharply pointed and unequal upper/lower beak [10]. Earlier classic ornithological studies indicated that powerful protractor quadrati and protractor pterygoidei muscles form a muscular shock absorber or distributor by holding the beak with resilient rigidity $[7,16,25]$. A more detailed study on the woodpecker's drilling behavior without brain injury was that of May et al., who dissected the heads of two woodpeckers (Phloeoceastes guatemalensis) [4]. They observed special anatomical structures in the woodpecker's head including the stout sharply pointed beak that makes it easy for woodpeckers to drill holes in building a nest or searching for prey; a long tongue called the hyoid bone that originates from the dorsum of the maxilla, passes through the right nostril, and divides into two parts between the eyes, with the two parts then arching over the superior portion of the skull and around the occiput by passing on either side of the neck, coming forward through the lower mandible, and uniting as one again below the forehead; a narrow subdural space and little cerebrospinal fluid; and a relatively small and smooth brain specially oriented to provide larger contact areas within the skull. A quarter of a century later, Ivan Schwab, an ophthalmologist at the University of California, shared the 2006 Ig Noble Prize for ornithology with May, by raising wide interest in May's neglected work [26,27]. Recently, the roles of the woodpecker's unique topology of the skull, special hyoid bone and little cerebrospinal liquid in decreasing shock stress have been quantified through numerical simulation. The fascinating hyoid bone has been thought to play the role of a safety belt in distributing the potential shearing force especially after impact $[4,6,15,26,28]$. The biomechanical effects of unequal upper/lower beak morphology (where the outer tissue layer covering the upper beak is $1.6 \mathrm{~mm}$ longer than that covering the lower beak, and the high-strength bone structure of the upper beak is about $1.2 \mathrm{~mm}$ shorter than that of the lower beak) have also been evaluated for woodpecker drumming [6]. Gibson proposed that the different orientation of the brain within the woodpecker's skull when compared with the orientation for the human might be the most important reason that brain injury is avoided at high-speed impact; the orientation of the brain in the woodpecker's skull increases the contact area between the brain and skull [19]. However, the overwhelming majority of birds have the same brain orientation within the skull as the woodpecker, and yet small birds can be knocked out by impacts that seem to be of the same order of magnitude as strikes made by the woodpecker; birds are commonly observed to tumble motionless and unconscious after flying head first into a window (although they pick themselves up and fly away later), which makes the woodpecker's resistance to head injury even more mysterious [5].

Simple theory based on head morphology alone may be misleading. To clarify the protective biomechanism, the material properties and micromorphology of the woodpecker's special hyoid bone, cranial bone and beak have been studied from the point of view of material science [6,14,29]. The hyoid bone has unique strength and flexibility owing to its unique micro/nano hierarchical composite structures. It consists of a flexible cartilage and bone skeleton covered with a thin tissue layer having high strength and elasticity. At the interface between the cartilage-bone skeleton and the tissue layer, there is a hierarchical fiber connection [14]. Bone is one of the most frequently investigated biological materials, owing to its primary function of providing skeletal stability. Bone is susceptible to different local stimuli, from 
mechanical properties to environmental changes [30]. The microstructure of the skull and beak of the great spotted woodpecker, in terms of the bone volume/total volume ratio (BV/TV) means that relative percentage of bone within 3-D ROI (\%), trabecular thickness (Tb.Th) that quantification of relative thickness of individual trabeculae within 3-D ROI (mm.), trabecular number (Tb.N) that quantification of relative number of individual trabeculae within 3-D ROI $(1 / \mathrm{mm})$, trabecular separation (Tb.Sp) that quantification of relative spacing between individual trabeculae within 3-D ROI (mm), structure model of index (SMI) that focus on quantification of relative shape of trabeculae from rod-like to plate-like, were investigated via micro-computed tomography [29]. In the case of the cranial bone, the SMI was lower and $\mathrm{Tb}$.Th and Tb.N were higher for the woodpecker than for other birds. In the case of the beak, the SMI, Tb.N, and BMD were all higher and Tb.Th was lower for the woodpecker than for other birds. More plate-like trabecular bone and greater thickness, greater numbers, and closer spacing of trabeculae in the woodpecker cranial bone may lead to less deformation during drumming, which would decrease the stress on the brain. Conversely, the greater quantity of rod-like structures and thinner trabeculae of the woodpecker's beak may lead to larger deformation during drumming. As the impact forces are absorbed and distributed by the beak, their transmission to the brain would be reduced. These micro-parameters combine to produce quite similar ultimate strengths of the beaks of the woodpecker and other birds. This suggests that the mechanical properties are sensitive to the shape of individual trabeculae [31]. Samples with higher contents of organic matter experience greater material loss on ignition. Materials that contain more organic material are expected to exhibit greater flexibility under load [32,33]. Both cranial bones had higher ignition losses than the beak bones, indicating that the proportions of bone mineral in the cranial bones were lower than those in the beak bones. The higher ignition loss in the beak bone of the woodpecker also implies that greater deformation may occur under impact stress. Thus, the applied impact stress could be partially absorbed by the beak bone and before transmission to the cranial bone. These distinctive mechanical properties, microstructure and composition of the woodpecker's cranial bone and beak provide excellent resistance to head impact injury at high speed and deceleration.

The above macro/micromorphology could work together to provide the woodpecker's impact resistance. These distinctive features provide excellent resistance to head impact injury at high speed and deceleration. The mechanical strength of bone is determined by the microstructure and the composition of the bone tissue [31,34]. Compared with the case for other birds, the cranial bone of the woodpecker has higher ultimate strength and resistance to impact injury as a result of its unique microstructure, including more plate-like trabecular bone, greater thickness, greater numbers, and closer spacing of trabeculae, and a higher proportion of bone mineral. Under high stress, the cranial bone and beak of the woodpecker exhibit distinctive mechanical features, which are associated with differences in microstructure and composition.

\section{Woodpecker-inspired shock-absorbing sys- tem or device}

The shock absorption mechanism of the woodpecker's head has become a meaningful research topic in the area of engineering. Scientists are also keen to develop new woodpecker-inspired safety devices to protect people from impacts. Inspired by the ability of the woodpecker to drum without suffering head injury, new bionic systems and devices based on the momentum transfer mechanism of the woodpecker have been developed [10-13].

Many features of the woodpecker's anatomy are associated with its ability to drill holes in trees. The beak is a chisel-shaped high-strength bone covered with horny keratin. The beak is attached to the skull by powerful muscles that contract before impact [17]. The pelvic bones are wide, allowing the attachment of strong muscles to the legs and tail; the power of a woodpecker's strike must be derived from the muscles in the body. Video analysis of a red-headed woodpecker ( $M$. erythrocephalus) showed momentum transfer along the neck. Additionally, the woodpecker's body moves with approximately sinusoidal motion, whereas the head moves with a more saw-tooth profile, reaching a higher velocity while striking, which suggests that the neck does not undergo a simple whiplash motion. Inspired by the nonlinear motion of the woodpecker's body as mentioned earlier, Vincent et al. [11] made a low-inertia lightweight hammer. The hammer was originally conceived for use in space exploration, where it has no net inertia until it comes into contact with an object, and even then the force delivered can be tuned. The bionic hammer thus has a number of advantages over conventional design that are based on the kinematics of the woodpecker. It could also be used where working space is at a premium, such as in dentistry or surgery, or in removing flash from castings.

Micro-vibrations of an environment include vibrations from the ground, the movement of instruments on a platform, and universal gravitational fluctuations. Vibrations in a frequency range from $1-100 \mathrm{~Hz}$ are generated by the movement of people, ventilation shafts, and even earthquakes [35]. As previously mentioned, the brain of the woodpecker can isolate vibrations well. When the woodpecker drums wood at high speed, its brain bears a blow that is 1000 times its own weight, without suffering damage. This ability is attributed to the special structure of the woodpecker's brain [7]. Inspired by the bionics mechanics and special organic texture of the woodpecker's brain, an active vibration isolation system using giant magnetostrictive actuators and air springs controlled by a neural network was developed by Mei et al. [10]. To isolate effectively the 
high-frequency vibrations received from the ground, a rubber layer was used to isolate vibrations passively between the pedestal of the micro-manufacturing platform and the ground. This layer corresponds to the cartilage and muscles in the outer meninges of the woodpecker's brain. Active vibration isolation was adopted to isolate vibrations between the micro-manufacturing platform and the pedestal. Air springs were used as elastic components, and corresponded to the interspaces between the outer meninges and the encephala of the woodpecker's brain. The actuator was made of strongly magnetostrictive material, and corresponds to the nerves and neural muscles linking the meninges and encephala. It was demonstrated in several vibration control experiments that the bionic vibration isolation system has good performance in response to floor disturbances. The active vibration isolation system was effective in isolating vibration disturbances of different frequencies transmitting from the pedestal, and could isolate low or ultra-low frequency vibrations, which are difficult to isolate with a passive vibration isolation system.

In recent years, there has been an increasing need for micro-machined electronic devices (MEDs) for military applications; micromachining technology is a powerful tool for miniaturization, low-power consumption and cost reduction [36,37]. In military applications such as shock-recording systems and hard-target smart-fuse systems, MEDs are exposed to mechanical shocks that concentrate significant amounts of mechanical energy into small regions in a short period of time [38-40]. Direct exposure to mechanical shocks with amplitude ranging up to $60000 \times g$ and frequency exceeding $100 \mathrm{kHz}$ causes structural damage to MEDs, in spite of their miniaturization. Mechanical excitations above $10 \mathrm{kHz}$ also seriously deteriorate the linear operation of any spring-mass-type MED such as a sensor or actuator. Therefore, an effective method for isolating MEDs from transient high-frequency mechanical excitations is in strong demand and appears to be one of the most remarkable achievements in the design of MEDs [41-44]. Biomimetically inspired from the spongy bone within a woodpecker's skull, Yoon et al. [12] presented woodpecker-inspired shock isolation with which to protect MEDs in high-g military applications accompanied by mechanical shock excitations to tens of thousands of $\mathrm{g}$ and to several hundred kilohertz. The biomimetically inspired shock isolation used a microgranular bed to protect MEDs. The shock phenomenon in the microgranular bed within a metal housing controls unwanted high-frequency mechanical excitations so that their adverse effects on the embedded MEDs are kept within an acceptable limit. Test results have verified that the woodpecker-inspired shock isolation is superior to conventional isolation using hard resin in terms of improving the shock survivability of MEDs. In the woodpecker-inspired shock isolation, the mechanical shocks transmitted to the MEDs are attenuated by kinetic energy absorption such as particle-to-particle collision and particle-to-particle or wall friction. Yoon et al. [13] then designed a new shock-absorbing system to protect commercial micro-machined devices from unwanted high-g accelerations with reference to the spongy bone in the skull of the woodpecker encompassed by the hyoid. The new shock-absorbing system consists of close-packed microglass within two metal enclosures and a viscoelastic layer fastened by steel bolts, and has been shown to remarkably improve g-force tolerance. In experimental characterizations using a $60-\mathrm{mm}$ smoothbore air-gun, the bio-inspired shock-absorbing system had a failure rate of $0.7 \%$ for commercial micro-machined devices at $60000 \times g$, whereas the conventional method of using hard resin had a failure rate of $26.4 \%$ [12,13].

\section{Summary}

Evolutionary optimization of the woodpecker's macro/ micromorphology has allowed the woodpecker to functionally adapt to its specific lifestyle. The woodpecker's head is a sophisticated shock absorption system employing cooperative mechanisms; i.e., no single factor is responsible for protecting the woodpecker's brain during drumming. The hyoid bone, the unequal upper/lower beak, the narrow subdural space and little cerebrospinal fluid, the relatively small and smooth brain, the dense yet spongy bone especially at the occiput, the orientation of the brain within the skull, and the lower ratio of brain weight to brain surface area give the woodpecker an advantage over the human when striking its head against a trunk $[4,5,45]$. Meanwhile, the powerful protractor quadrati and protractor pterygoidei muscles and the unequal lengths of the upper/lower beak provide a shock absorber and distributor that holds the bill in resilient rigidity $[6,7,16,17,25]$. Analyzing the results of previous studies, it is concluded that the woodpecker's shock absorption arrangement has a number of features. Woodpeckers are also considered a testament to the superiority of bioengineering design. Knowledge of the biomechanism of the woodpecker's ability to resist impact injury to the head and the material properties and distribution of the shock-absorbing spongy bone could be incorporated into the design of new safety helmets, sports products and other devices that need to be able to resist impact. In addition, better understanding of the biomechanism and materials would suggest new structures of shock-absorbing composite materials in engineering.

This work was supported by the National Natural Science Foundation of China (10925208, 11120101001, 11202017, 11272038), Beijing Natural Science Foundation (7133245), Young Scholars for the Doctoral Program of Ministry of Education of China (20121102120039) and the Hong Kong Polytechnic University (G-U624).

1 Martin E, Lu W, Helmick K, et al. Traumatic brain injuries sustained in the Afghanistan and Iraq wars. Am J Nurs, 2008, 108: 40-47 
2 Park E, Bell C J D, Baker A J. Traumatic brain injury: can the consequences be stopped? Can Med Assoc, 2008, 178: 1163-1170

3 Powell J W. Cerebral concussion: causes, effects, and risks in sports. J Athl Train, 2001 36: 307-311

4 May P, Fuster J, Newman P, et al. Woodpeckers and head injury. Lancet, 1976, 1: 454-455

5 May P R, Fuster J M, Haber J, et al. Woodpecker drilling behavior-an endorsement of the rotational theory of impact brain injury. Arch Neurol, 1979, 36: 370-373

6 Wang L, Cheung J T, Pu F, et al. Why do woodpeckers resist head impact injury: a biomechanical investigation. PLoS ONE, 2011, 6: e26490

7 Spring L W. Climbing and pecking adaptations in some north American woodpecker. Condor, 1965, 67: 457-488

8 Bock W J. An approach to the functional analysis of bill shape. Auk, 1966, 83: 10-51

9 Rubner M. Materials science: synthetic sea shell. Nature, 2003, 423: 925-926

10 Mei D, Yang K, Chen Z. Design of an ultra-precision vibration isolation system by imitating the special organic texture of woodpecker's brain. In: Proceedings of the 2004 IEEE Conference on Robotics, Automation and Mechatronics, Singapore, 2004

11 Vincent J F V, Sahinkaya M N, O'Shea W. A woodpecker hammer. In: Proceedings of the Institution of Mechanical Engineers Part C: Journal of Mechanical Engineering Science, 2007

12 Yoon S H, Roh J E, Kim K L. Woodpecker-inspired shock isolation by microgranular bed. J Phys D Appl Phys, 2009, 42: 035501-1035501-8

13 Yoon S H, Park S. A mechanical analysis of woodpecker drumming and its application to shock-absorbing systems. Bioinspir Biomim, 2011, 6: 016003

14 Zhou P, Kong X Q, Wu C W, et al. The novel mechanical property of tongue of a woodpecker. J Bionic Eng, 2009, 6: 214-218

15 Oda J, Sakamoto J, Sakano K. Mechanical evaluation of the skeletal structure and tissue of the woodpecker and its shock absorbing system. JSME Int J Ser A, 2006, 49: 390-396

16 Bock W J. Kinetics of the avian skull. J Morphol, 1964, 114: 1-41

17 Bock W J. Functional and evolutionary morphology of woodpecker. Ostrich, 1999, 70: 23-31

18 Mlikovsky J. Brain size in birds: 3. Columbiformes through Piciformes. Vestn Cesk Spol Zool, 1989, 53: 252-264

19 Gibson L J. Woodpecker pecking: how woodpeckers avoid brain injury. J Zool, 2006, 270: 462-465

20 Holbourn A H S. Mechanics of head injuries. Lancet, 1943, 2: 438441

21 Ommaya A K, Gennarelli A T. Cerebral concussion and traumatic unconsciousness: correlation of experimental and clinical observations on blunt head injuries. Brain, 1974, 97: 97

22 Ommaya A K, Hirsch A E. Tolerances for cerebral concussion from head impact and whiplash in primates. J Biomech, 1971, 4: 13-31

23 Sielmann H. My year with the woodpeckers 1959. London: Barrier and Rockliff, 1959. 139

24 King A I, Yang K H, Zhang L, et al. Is head injury caused by linear or angular acceleration. In: IRCOBI Conference, Lisbon, Portugal, 2003
25 Beecher W J. Feeding adaptations and systematics in the avian order Piciformes. J Washington Acad Sci, 1953, 43: 293-299

26 Schwab I R. Cure for a headache. British J Ophthalmol, 2002, 86: 843

27 Nadis S. Hard-hitting endeavour captures Ig Nobel. Nature, 2006, 443: 616-617

28 Cho Y J. Damping System in Woodpecker's Head. Reports of Korea Advanced Institute of Science and Technology, 2002

29 Wang L, Zhang H, Fan Y. Comparative study of the mechanical properties, micro-structure, and composition of the cranial and beak bones of the great spotted woodpecker and the lark bird. Sci China Life Sci, 2011, 54: 1036-1041

30 Müller R. Hierarchical microimaging of bone structure and function. Nat Rev Rheumatol, 2009, 5: 373-381

31 Ciarelli M J, Goldstein S A, Kuhn J L, et al. Evaluation of orthogonal mechanical properties and density of human trabecular bone from the major metaphyseal regions with materials testing and computed tomography. J Orthop Res, 1991, 9: 674-682

32 Koutsopoulos S. Synthesis and characterization of hydroxyapatite crystals: a review study on the analytical methods. J Biomed Mater Res, 2002, 62: 600-612

33 Kandori K, Horigami N, Yasukawa A, et al. Texture and formation mechanism of fibrous calcium hydroxyapatite particles prepared by decomposition of calcium-EDTA chelates. J Am Ceram Soc, 1997, 80: $1157-1164$

34 Dalen N, Hellstrom L G, Jacobson B. Bone mineral content and mechanical strength of the femoral neck. Acta Orthop Scand, 1976, 47: 503-508

35 Zhang C L, Mei D Q, Chen Z C. Active vibration isolation of a micro-manufacturing platform based on a neural network. J Mater Proc Technol, 2002, 129: 634-639

36 Brown T G, Davis B, Hepner D, et al. Strap-down microelectromechanical (MEMS) sensors for high-G munition applications. IEEE Trans Magn, 2001, 37: 336-342

37 Yoon S H, Son J T, Oh J S. Miniaturized g- and spin-activated $\mathrm{Pb} /$ $\mathrm{HBF} 4 / \mathrm{PbO} 2$ reserve batteries as power sources for electronic fuzes. J Power Sources, 2006, 162: 1421-1430

38 Gupta Y M, Sharma S. Shocking matter to extreme conditions. Science, 1997, 277: 909-910

39 Yoon S H, Kim K L. Passive low pass filtering effect of mechanical vibrations by a granular bed composed of microglass beads. Appl Phys Lett, 2006, 89

40 Alexander R M, Bennet-Clark H C. Storage of elastic strain energy in muscle and other tissues. Nature, 1977, 265: 114-117

41 Britan A, Ben-Dor G, Igra O, et al. Shock waves attenuation by granular filters. Int J Multiphase Flow, 2001, 27: 617-634

42 Bakken J, Slungaard T, Engebretsen T, et al. Attenuation of shock waves by granular filters. Shock Waves, 2003, 13: 33-40

43 Veprik A M, Babitsky V I. Vibration protection of sensitive electronic equipment from harsh harmonic vibration. J Sound Vib, 2000, 238: 19-30

44 Bhatti R A, Wang Y R, Wang Z C. Particle impact damping in two dimensions. Key Eng Mater, 2009, 413-414: 415-422

45 Self Z. Why don't woodpeckers get headaches? J Exp Biol, 2012, 215: V-VI

Open Access This article is distributed under the terms of the Creative Commons Attribution License which permits any use, distribution, and reproduction in any medium, provided the original author(s) and source are credited. 